\title{
Effect of a general practitioner's consulting style on patients' satisfaction: a controlled study
}

\author{
Richard Savage, David Armstrong
}

\begin{abstract}
Objective-To compare the effect of directing and sharing styles of consultation by a general practitioner on patients' satisfaction with the
\end{abstract} consultation.

Design-Patients were randomised to receive a directing or sharing style in the part of the consultation concerned with giving treatment, advice, and prognosis.

Setting-An inner London general practice.

Patients-359 Randomly selected patients consulting with one general practitioner. Four patients refused to participate and five were excluded. Thirty failed to complete the initial assessment and 110 failed to complete the assessment a week later, giving response rates of $89 \%$ and $58 \%$ respectively.

Main outcome measures-Patients' satisfaction standing of their problem and the explanation they received and whether they felt that they had been helped immediately after the consultation and one week later.

Results-Patients who had the directing style of consultation reported significantly higher levels of satisfaction on almost all the outcome measures. physical problems (excellent explanation 23/68 (34\%) $v 10 / 65(15 \%), \mathrm{p}<0.02$; excellent understanding $25 / 68(37 \%) v 9 / 66(14 \%), p=0.004)$, and for patients who received a prescription (excellent explanation 20/60 (33\%) v 9/59 (15\%), $\mathbf{p}<0.04$; excellent understanding $27 / 60(45 \%) v 10 / 59(17 \%), \mathrm{p}=0 \cdot 04)$. There was no significant difference in the responses to the directing and sharing styles in longer consultations was advice $(10 / 30(33 \%) v 7 / 36(19 \%))$, and among patients with psychological $(6 / 17(35 \%) v 6 / 27(22 \%))$ or chronic problems $(14 / 28(50 \%) v 8 / 32(25 \%))$.

Conclusions-Style of consultation does influence Stockwell Group Practice, Buckmaster House, Stockwell Park Estate, London SW9 0UB Richard Savage, MRCGP, general practitioner

Department of General Practice, United Medical and Dental Schools of Guy's and St Thomas's Hospitals (Guy's Campus), London SE1 9RT

David Armstrong, FFPHM, reader in sociology as applied to medicine

Correspondence to: Dr Savage. most noticeable in consultations with patients with physical problems and patients who receive a prescription.

\section{Introduction}

Several studies over the past decade have reported the benefits of general practitioners adopting a sharing style during consultations. ${ }^{2}$ These studies have argued that by making patients part of the process of making decisions the doctor becomes clearer about the nature of the patient's problem and the patient is more committed to any advice given. The result is a more satisfied patient who will be more likely to follow medical advice.

Another tradition in medicine, however, argues that the doctor's primary function is to make the patient feel better by invoking authoritarianism, paternalism, with the general practitioner's perceived underThis was particularly striking for patients with $(8 / 31(26 \%) v 8 / 31(26 \%))$, in which the main treatment

and domination-qualities said to be essential for effectiveness in medicine. ${ }^{3}$ Recent work by Thomas has suggested that patients presenting with symptoms bùt no physical signs may respond better to a "directive" style of consultation when speed of recovery is the measure of outcome. ${ }^{4}$

The problem with this debate is that the evidence has tended to be circumstantial. Many of the studies have omitted a control group of patients, who are difficult to enter into such studies. It would probably be unethical to enter patients into such studies without preliminary screening, which could introduce serious bias.

Because of the importance of this debate for general practice and the need for better experimental design we assessed the effects of randomly varying the style of consultation in the part of the consultation when advice and treatment were given. This design overcame the ethical problem of assignment as patients judged inappropriate to enter the study could be excluded. Because of the reported beneficial effects of a sharing style on patients' satisfaction we used patients' satisfaction as a measure of the success of the consultation immediately after the consultation and one week later.

\section{Patients and methods}

The study was done in a group practice in a deprived inner city area. A full appointment system operated, and patients were free to choose which doctor they saw. A random number generator was used to select, in advance, four patients for the study from each surgery held by one general practitioner (RS) over four months. Patients aged 16 to 75 presenting with any symptom were eligible; they were excluded if they presented with a life threatening condition or for administrative or preventive measures only. Patients were also excluded if RS thought that they would be upset by taking part in the study or would be incapable of completing a part of it.

We obtained patients' consent for the study by the satisfaction of the patient, but its effect 
room a stopwatch was started and the consultation opened with a standard greeting and encouragement to describe the problem. The card that allocated the style was turned over only when the patient had completed his or her description of the initial problem and had been identified as suitable for entry to the study. Advice and treatment were then given in the allocated style, the prompt card being checked to ensure that all parts of the consultation were covered appropriately. At the end of the consultation the time was noted and the patient was asked to complete the questionnaire in the waiting room and give it to the receptionist before leaving the surgery. A second questionnaire with a stamped addressed envelope was then given to each patient with instructions to fill it in and post it after one week. After the patient had left the consulting room demographic and other data were gathered from the notes and the length of the consultation was recorded.

The data collected were entered into a personal computer and analysed with the statistical package for the social sciences.

TABLE I-Examples of directing and sharing styles of consultation by general practitioner during five parts of consultation

\begin{tabular}{|c|c|c|}
\hline \multirow[b]{2}{*}{ Part of consultation } & \multicolumn{2}{|c|}{ Style of consultation } \\
\hline & Directing & Sharing \\
\hline Judgment on the consultation & $\begin{array}{l}\text { "This is a serious problem" or } \\
\text { "I don't think this is a serious } \\
\text { problem" }\end{array}$ & $\begin{array}{l}\text { "Why do you think this has happened?" } \\
\text { "Why do you think this has happened } \\
\text { now?" }\end{array}$ \\
\hline Diagnosis & "You are suffering from ..." & "What do you think is wrong?" \\
\hline Treatment & $\begin{array}{l}\text { "It is essential that you take this } \\
\text { medicine" }\end{array}$ & $\begin{array}{l}\text { "What have you tried to do to help so } \\
\text { far?" } \\
\text { "What were you hoping that I would be } \\
\text { able to do?" } \\
\text { "Would you like a prescription?" } \\
\text { "I think this medicine would be helpful; } \\
\text { would you be prepared to take it?" }\end{array}$ \\
\hline Prognosis & "You should be better in ... days" & $\begin{array}{l}\text { "What do these symptoms or problems } \\
\text { mean to you?" }\end{array}$ \\
\hline Follow up and closure & $\begin{array}{l}\text { "Come and see me in ... days" } \\
\text { "I don't need to see you again for this } \\
\text { problem" }\end{array}$ & $\begin{array}{l}\text { "Are there any other problems?" } \\
\text { "When would you like to come and see } \\
\text { me again?" }\end{array}$ \\
\hline
\end{tabular}

TABLE II -Effect of doctor's style of consultation on assessment of his understanding of their problem by patients immediately after consultation. Figures are numbers (percentages) of patients ( $n=320$ )

\begin{tabular}{|c|c|c|c|}
\hline \multirow[b]{2}{*}{ Assessment } & \multicolumn{2}{|c|}{ Style of consultation } & \multirow[b]{2}{*}{ Significance } \\
\hline & Directing & Sharing & \\
\hline $\begin{array}{l}\text { I was able to discuss my problem well } \\
\text { I received an excellent explanation } \\
\text { I perceived the general practitioner to have complete }\end{array}$ & $\begin{array}{r}130 / 157(83) \\
63 / 162(39)\end{array}$ & $\begin{array}{r}132 / 154(86) \\
41 / 156(26)\end{array}$ & $\chi^{2}=5 \cdot 7 ; \mathrm{df}=1 ; p=0 \cdot 02$ \\
\hline $\begin{array}{l}\text { understanding } \\
\text { I felt greatly helped } \\
\text { I felt much better }\end{array}$ & $\begin{array}{l}86 / 162(53) \\
77 / 162(48) \\
45 / 162(28)\end{array}$ & $\begin{array}{l}61 / 158(39) \\
66 / 156(42) \\
48 / 155(31)\end{array}$ & $\begin{array}{c}\chi^{2}=6 \cdot 8 ; \mathrm{df}=1 ; p=0.01 \\
\text { NS } \\
\text { NS }\end{array}$ \\
\hline
\end{tabular}

\section{Results}

Overall, 359 patients were invited to take part in the study. Of these, four declined to participate and five were excluded (three had schizophrenia, one had manic depression, and one was a mentally subnormal adult subject to a court protection order). Thirty patients failed to complete the initial assessment, and 120 failed to complete the assessment a week later, giving response rates of $89 \%$ and $56 \%$ respectively. There were no significant differences in terms of age, sex, ethnic origin, presenting problem, or allocated style between the responders and non-responders at both the initial and second assessments.

An independent observer analysed 40 random tape recordings of consultations and confirmed that all aspects of the protocol had been covered in every consultation. The intended style was correctly identified in all but one of the consultations.

There were no significant differences in the mean length of consultations between the two experimental groups (sharing style $=8.89$ minutes, directing style $=$ 8.85 minutes)

The patients reported a high overall level of satisfaction with their consultations, only three giving neutral or dissatisfied responses to any of the questions asked. Table II shows that the patients' assessment of the doctor's understanding of their problem and the adequacy of the explanation received immediately after the consultation significantly favoured the directing style.

When the responses of the 200 patients who completed both assessments were analysed a significantly higher proportion of the patients who had had the directing style of consultation indicated that they had received an excellent explanation and that the general practitioner had had a complete understanding of their problem both immediately and after one week (table III). In addition, after one week patients who had received the directing style were more likely to report that they had been greatly helped. The assessments of satisfaction with the doctor in terms of explanation, understanding, and the feeling that they had been helped had all declined significantly by the one week assessment (Wilcoxon paired test, $\mathrm{p}<0 \cdot 001$ ). When specific characteristics of the consultation were analysed the directing style produced a significantly better perception of the doctor's explanation and understanding after one week among patients who rarely attended surgery, those whom he thought had a physical problem, those whom he did not investigate, and those who received a prescription (table IV). By contrast,. four characteristics of the consultation

TABLE III-Effects of doctor's style of consultation on assessment of his understanding of their problem by 200 patients who completed questionnaires initially and one week later. Figures are numbers (percentages) of patients

\begin{tabular}{|c|c|c|c|c|c|c|}
\hline \multirow[b]{2}{*}{ Assessment } & \multicolumn{3}{|c|}{ Initially } & \multicolumn{3}{|c|}{ One week later } \\
\hline & $\begin{array}{l}\text { Directing } \\
\text { style }\end{array}$ & $\begin{array}{c}\text { Sharing } \\
\text { style }\end{array}$ & Significance & $\begin{array}{l}\text { Directing } \\
\text { style }\end{array}$ & $\begin{array}{l}\text { Sharing } \\
\text { style }\end{array}$ & Significance \\
\hline $\begin{array}{l}\text { I was able to discuss my problem well } \\
\text { I received an excellent explanation } \\
\text { I perceived the general practitioner to have complete understanding } \\
\text { I felt greatly helped } \\
\text { I felt much better }\end{array}$ & $\begin{array}{l}79 / 96(73) \\
44 / 97(45) \\
60 / 97(62) \\
52 / 97(54) \\
32 / 97(33)\end{array}$ & $\begin{array}{l}75 / 102(74) \\
24 / 101(24) \\
38 / 103(37) \\
45 / 100(45) \\
32 / 100(32)\end{array}$ & $\begin{array}{l}\text { NS } \\
\chi^{2}=10 \cdot 2 ; \mathrm{df}=1 ; p=0 \cdot 001 \\
\chi^{2}=12 \cdot 5 ; \mathrm{df}=1 ; p=0 \cdot 0004 \\
\text { NS } \\
\text { NS }\end{array}$ & $\begin{array}{l}55 / 90(61) \\
30 / 90(33) \\
35 / 90(39) \\
44 / 89(49) \\
29 / 89(33)\end{array}$ & $\begin{array}{l}50 / 95(53) \\
16 / 96(17) \\
17 / 96(18) \\
27 / 97(28) \\
25 / 97(26)\end{array}$ & $\begin{array}{l}\mathrm{NS} \\
\chi^{2}=6 \cdot 7 ; \mathrm{df}=1 ; p=0.009 \\
\chi^{2}=10 \cdot 3 ; \mathrm{df}=1 ; p=0 \cdot 001 \\
\chi^{2}=9 \cdot 2 ; \mathrm{df}=1 ; p=0.002 \\
\quad \text { NS }\end{array}$ \\
\hline
\end{tabular}

TABLE IV-Numbers (percentages) of patients who reported receiving excellent explanation and achieving excellent understanding with directing and sharing styles of consultation after one week according to subgroup

\begin{tabular}{|c|c|c|c|c|c|c|}
\hline \multirow[b]{2}{*}{ Subgroup of patients } & \multicolumn{3}{|c|}{ Excellent explanation } & \multicolumn{3}{|c|}{ Excellent understanding } \\
\hline & $\begin{array}{l}\text { Directing } \\
\text { style }\end{array}$ & $\begin{array}{l}\text { Sharing } \\
\text { style }\end{array}$ & Significance & $\begin{array}{l}\text { Directing } \\
\text { style }\end{array}$ & $\begin{array}{l}\text { Sharing } \\
\text { style }\end{array}$ & Significance \\
\hline $\begin{array}{l}\text { Attended infrequently } \\
\text { Had a problem assessed as physical by doctor } \\
\text { Did not have any tests } \\
\text { Received a prescription }\end{array}$ & $\begin{array}{l}17 / 55(31) \\
23 / 68(34) \\
24 / 76(32) \\
20 / 60(33)\end{array}$ & $\begin{array}{r}9 / 65(14) \\
10 / 65(15) \\
12 / 80(15) \\
9 / 59(15)\end{array}$ & $\begin{array}{l}\chi^{2}=4 \cdot 1 ; \mathrm{df}=2 ; \mathrm{p}<0.04 \\
\chi^{2}=5 \cdot 1 ; \mathrm{df}=2 ; \mathrm{p}<0.02 \\
\chi^{2}=5 \cdot 1 ; \mathrm{df}=2 ; \mathrm{p}<0.02 \\
\chi^{2}=4 \cdot 3 ; \mathrm{df}=2 ; \mathrm{p}<0.04\end{array}$ & $\begin{array}{l}22 / 55(40) \\
25 / 68(37) \\
30 / 76(40) \\
27 / 60(45)\end{array}$ & $\begin{array}{r}11 / 65(17) \\
9 / 66(14) \\
13 / 81(16) \\
10 / 59(17)\end{array}$ & $\begin{array}{l}\chi^{2}=6.8 ; \mathrm{df}=2 ; \mathrm{p}<0.009 \\
\chi^{2}=8.3 ; \mathrm{df}=2 ; \mathrm{p}<0.004 \\
\chi^{2}=9.7 ; \mathrm{df}=2 ; \mathrm{p}<0.002 \\
\chi^{2}=4.4 ; \mathrm{df}=2 ; \mathrm{p}<0.04\end{array}$ \\
\hline
\end{tabular}


produced no significant differences in perceived explanation, understanding, and helpfulness between the two groups-namely, consultations that were longer than nine minutes $(8 / 31(26 \%) v 8 / 31(26 \%))$; those in which the main treatment was advice $(10 / 30$ $(33 \%) v 7 / 36(19 \%))$; those judged by the general practitioner to be for a chronic problem (14/28 (50\%) $v$ $8 / 32(25 \%))$; and those for conditions that the patient thought had a psychological basis $(6 / 17(35 \%) v 6 / 27$ $(22 \%))$.

\section{Discussion}

We aimed to determine whether the doctor's style of giving advice, treatment, and prognosis could affect the outcome of the consultation. Our results suggest that the directing style had a better effect in terms of patients' satisfaction as measured by their perception of the doctor's understanding of the problem, the quality of the doctor's explanation, and the subjective improvement one week later. This would support Inglefinger's assertion that authoritarianism, paternalism, and certainty are elements of the doctor's style that satisfy patients most. ${ }^{3}$ These results contradict both conventional wisdom and the subjective experience of those doctors who have developed a sharing style and believe that sharing possibilities, uncertainty, and decisions about treatment leads to a more adult relationship with patients. But given the design of the study could the results be interpreted differently?

Possibly, despite the attempt at random allocation, the two groups of patients were different; the different characteristics of patients rather than the styles of consultation would then have produced the different results. The results suggest that this is not an important factor because, firstly, there were no sociodemographic differences between the patients in the two groups and, secondly, the question asking if they had been able to discuss the problem well yielded similar responses in the two groups. Given that the consultations up to this point were conducted identically, this confirms that random allocation had been done successfully.

The measures of satisfaction used - namely, quality of explanation, perceiving the general practitioner to have understood the problem, and feeling greatly helped-were not obviously biased against a sharing style of consultation, so this cannot account for the observed differences. Indeed, these assessments might be expected to be enhanced by a sharing style.

Another possibility is that the general practitioner did not vary his style, but this is unlikely as analysis of tape recorded consultations by an independent observer showed clear differences between the two groups. Moreover, the significant differences between the groups suggest that they had each experienced different types of consultation.

The differences in style, however, occurred only after the nature of the problem had been established, and it might be argued that these results show that consistency of the doctor's style during a consultation, particularly one that meets patients' expectations, is important. Some patients may be attracted to or adapt to a doctor's natural style and then be nonplussed by a sudden change.

Equally, the nature of the underlying medical problem seemed to affect the satisfaction with the different styles. Thus a directing style did not seem to give greater satisfaction in longer consultations; those in which advice was the main treatment; for those patients whom the doctor judged to have a chronic illness; or for patients who judged themselves to have a psychological illness. It was, however, a clear benefit for those patients whom the general practitioner thought had mainly physical problems and those who received a prescription. This suggests a possible congruence between two broad types of illness and specific styles. Simple physical illness that responds to the traditional biomedical approach of diagnosis and treatment would seem to benefit from a directing style. For other problems, however, particularly chronic and psychological illnesses that have a recognisable, large psychosocial component and that the traditional biomedical model manages poorly, the benefit disappears. Patients' assessment of their illness might influence their expectations of their doctor so that different styles might be preferred in different situations.

The difference between patients' assessments in the two groups needs to be examined further in the light of the overall decline in assessments over time. All the evaluations of the doctor's performance declined over the succeeding week. This effect was often more noticeable than the differences attributable to style. This supports the suggestion of Pendleton et al that levels of satisfaction may reflect the immediate impact of the consultation but longer held attitudes and opinions have more influence on medium and long term results than a single encounter with the doctor ${ }^{6}$

Our results again show the importance of style on satisfaction with the consultation. Future randomised studies that try to remove extraneous variables in the design may clarify this problem and show the extent to which patients accommodate and benefit from their doctor's style in different clinical situations.

This study was based on a project completed as part of an MSc in general practice at the United Medical and Denta Schools. We thank the patients who helped with this study, which was supported by the Royal College of General Practitioners Schering scholarship.

1 Katon W, Kleinman A. Doctor-patient negotiation and other social science strategies in patient care. In: Eisenberg L, Kleinman A, eds. The relevance of social science for medicine. Dordrecht: Reidel, 1980:253-83.

2 Tuckett D, Boulton M, Olsen C, Williams A. Meetings between experts: an approach to sharing ideas in medical consultations. London: Tavistock, 1985.

Inglefinger FJ. Arrogan N Engl f M d 1980;303:1507-11.

4 The KB. The consutation and the herapeutic illusion, $B r$ Med $f$ 1978;i:1327-8.

5 Noruisis MJ. The SPSS guide to data analysis. Chicago: SPSS, 1987.

6 Pendleton D, Schofield T, Tate P, Havelock P. The consultation: an approach to learning and teaching. Oxford: Oxford University Press, 1984:36.

(Accepted 8 August 1990)

\section{THE MEMOIR CLUB}

Problem solving in science is both an artistic and an intellectual exercise in which its devotees, well prepared by study, first jump to inspired conclusions, and then apply a rigid discipline in an attempt to prove themselves wrong with that curious combination of flair and constraint which has achieved so many miracles. It is by discarding or refining old concepts that we make way for new advance and so bring our minds a little closer to a true understanding. If not taken too seriously, and properly laced with humour and a little humility, this can become a most exciting way of life. Exciting, that is, for its practitioners but still apt to be rather remote from ordinary men and women, not yet initiated, who view with some justifiable anxiety such things as the meetings of scientists in conclave, their growing use of excluding jargon, and the harnessing of nuclear energy.

The combination of such scientific problem solving with medical practice offers one of the most rewarding ways of life imaginable. The excitement is there in sufficient measure to lift the spirit despite the fact that much research is pure drudgery, while the practical work of caring for patients, not always the most refined form of activity, never fails to keep a man's feet on the ground. To combine science with service is to satisfy both a natural curiosity and a fancy for usefulness.

From Not a Moment to Lose by David Smithers. Published under the BMF's Memoir Club imprint. ISBN 072790278 4. Price: Inland $£ 14.95$; abroad $£ 17.50$. BMA members: Inland £13.95; abroad $£ 16.50$. 